\title{
Cholesterol Self-Powered Biosensor
}

Alina Sekretaryova, Valerio Beni, Mats Eriksson, Arkady A. Karyakin, Anthony Turner and Mikhail Vagin

Linköping University Post Print

Tweet

N.B.: When citing this work, cite the original article.

Original Publication:

Alina Sekretaryova, Valerio Beni, Mats Eriksson, Arkady A. Karyakin, Anthony Turner and Mikhail Vagin, Cholesterol Self-Powered Biosensor, 2014, Analytical Chemistry, (86), 19, 9540-9547.

http://dx.doi.org/10.1021/ac501699p

Copyright: (C) 2014 American Chemical Society http://pubs.acs.org/

Postprint available at: Linköping University Electronic Press

http://urn.kb.se/resolve?urn=urn:nbn:se:liu:diva-112176 


\section{A cholesterol self-powered biosensor}

Alina N. Sekretaryova ${ }^{1}$, Valerio Beni ${ }^{1}$, Mats Eriksson ${ }^{1}$, Arkady A. Karyakin ${ }^{2}$, Anthony P.F. Turner $^{1 *}$, Mikhail Yu. Vagin ${ }^{1 *}$

${ }^{1}$ Department of Physics, Chemistry and Biology, Linköping University, SE-581 83, Linköping, Sweden

${ }^{2}$ Faculty of Chemistry, M.V. Lomonosov Moscow State University, Lenin's Hills, 119991, Moscow, Russia

*Corresponding authors

Mikhail Yu. Vagin

Email: mikhail.vagin@liu.se

Phone: $+46(0) 702753087$

Anthony P.F. Turner

Email: anthony.turner@liu.se

Phone: +46 (0) 13282604

Mobile: +46 (0) 734607558 


\section{ABSTRACT}

Monitoring the cholesterol level is of great importance, especially for people with high risk of developing heart disease. Here we report on reagentless cholesterol detection in human plasma with a novel single-enzyme, membrane-free, self-powered biosensor, in which both cathodic and anodic bioelectrocatalytic reactions are powered by the same substrate. Cholesterol oxidase was immobilised in a sol-gel matrix on both the cathode and the anode. Hydrogen peroxide, a product of the enzymatic conversion of cholesterol, was electrocatalytically reduced, by the use of Prussian blue, at the cathode. In parallel, cholesterol oxidation catalysed by mediated cholesterol oxidase occurred at the anode. The analytical performance was assessed for both electrode systems separately. The combination of the two electrodes, formed on high surface-area carbon cloth electrodes, resulted in a self-powered biosensor with enhanced sensitivity $\left(26.0 \mathrm{~mA} \mathrm{M} \mathrm{cm}^{-1}\right)$, compared to either of the two individual electrodes, and a dynamic range up to $4.1 \mathrm{mM}$ cholesterol. Reagentless cholesterol detection with both electrochemical systems and with the self-powered biosensor was performed and the results were compared with the standard method of colorimetric cholesterol quantification.

Keywords: self-powered biosensor, cholesterol biosensor, plasma, mediated electron transfer, Prussian blue, phenothiazine, sol-gel membrane 


\section{INTRODUCTION}

The determination of blood cholesterol is required for the assessment of atherosclerosis and other lipid-related disorders and for estimation of the risk of thrombosis and myocardial infarction ${ }^{1}$. Normal concentration of total cholesterol in blood should be less than $5.17 \mathrm{mM}$, the value can vary from person to person and depends on age, weight and gender. The borderline high level for total cholesterol concentration in human blood is defined as $5.17-6.18 \mathrm{mM}$ (typically corresponding to about $2 \mathrm{mM}$ free cholesterol); the high level is defined as above $6.21 \mathrm{mM}^{2}$. Thus, a highly sensitive cholesterol determination to differentiate these levels is very important for medical diagnostics.

Most of the commonly used techniques for free $(\sim 30 \%)^{3}$ and esterified cholesterol determination involve a prolonged analysis time, expensive equipment and trained personnel. Electrochemical biosensors combine the advantages of specific biorecognition with low-cost, facilitating convenient and rapid cholesterol quantification (e.g. CardioCheck "Cholesterol and glucose test monitors" by Polymer Techology Systems Inc. (PS-003528 ER1 1005), Cholestrack "Cholesterol Testers" by AccuTech, LLC, USA (US Pat. № 5340539) ${ }^{4}$.

Most of the current biosensors use cholesterol oxidase (ChOx), which specifically catalyses the oxidation of cholesterol by molecular oxygen to 4-cholesten-3-one and hydrogen peroxide. Different design strategies have been utilised for the development of electrochemical cholesterol biosensors including oxidation by mediated $\mathrm{ChOx}{ }^{5-10}$ or hydrogen peroxide monitoring by horse radish peroxidase ${ }^{11,12}$ or by inorganic catalysts ${ }^{13}$ and nanostructures ${ }^{14-16}$. Despite of the variety of reported cholesterol electrochemical biosensors ${ }^{4}$, only few of them have been shown to operate in whole blood ${ }^{17-19}$. An amperometric biosensor based on ChOx entrapped inside a composite polypyrrole-hydrogel membrane showed excellent correlation with results obtained by the standard method ${ }^{17}$ for total cholesterol determination in cholesterol esterase (ChEt) pretreated serum samples. Kumar et al. have developed an electrochemical biosensor, based on covalent coimmobilisation of ChOx and ChEt onto an electrode modified with a biocompatible self-assembled 
monolayer for total cholesterol quantification in undiluted serum samples ${ }^{18}$. Zhu et al. have reported a biosensor based on direct electron transfer of ChOx immobilised on multiwalled carbon nanotubes decorated with gold nanoparticles for free cholesterol measurements in entire human serum ${ }^{19}$. While significant progress has been made, there remains room for improvement in sensitivity, simplicity and cost. Self-powered electrochemical sensors, i.e. fuel cells with power output as an analytical signal proportional to the analyte concentration, have a series of advantages: (i) these analytical devices have a simple design of only two electrodes; (ii) biosensors with this configuration are powered by biological fluids opening the possibility for fabrication of autonomous sensing devices and power sources; and (iii) the possible development of inexpensive screening devices based on printed electronics ${ }^{20}$. Fuel-cell based biosensors first appeared in the literature in the 1980's ${ }^{21,22}$. The first commercial self-powered glucose biosensors were produced by Kyoto Daiichi Kagagu in Japan in 1996 and marketed as the Glucocard ${ }^{\mathrm{TM}}{ }^{23}$. Self-powered biosensors were later revived in the academic literature by Katz et al. ${ }^{24}$ who reported detection of either glucose or lactate over the concentration range $1-80 \mathrm{mM}$ by the measurement of power output variation with analyte (fuel) concentrations ${ }^{24}$. Subsequent works in a similar direction have included analytes such as glucose ${ }^{25}$, cyanide ${ }^{26}$ and mercury ion ${ }^{27}$. A self-powered sensor for ascorbic acid has been developed with Prussian blue (PB) as an electrochromic display ${ }^{28}$. A selfcharging supercapacitor based on mediated glucose oxidase has also been reported recently ${ }^{29}$. To the best of our knowledge there is no research published on a self-powered cholesterol biosensor. Despite the mentioned advantages with self-powered electrochemical biosensors, many previous devices suffered from a drawback: the use of two enzymes. This increases the cost. Also enzymes might have different optimum conditions ${ }^{30}$. These issues could be overcome by employing the same biocatalyst for both the anodic and the cathodic reactions driven by the same substrate, hence potentially improving efficiency and cost. There is only one report of a biofuel cell powered by the same substrate ${ }^{31}$. The anodic reaction was based on mediated GOx, whereas the cathodic 
reaction exploited GOx with peroxide transduction by co-immobilised horseradish peroxidase. This configuration still requires two enzymes.

Here we report a novel concept of a single-enzyme, membrane-free, self-powered biosensor employed for electrochemical biosensing of free cholesterol. Firstly, hydrogen peroxide generation as a result of cholesterol conversion by $\mathrm{ChOx}$ was monitored by electrocatalytic reduction on a Prussian Blue (PB)-modified electrode. The second electrocatalytic reaction involved cholesterol oxidation resulting from electron transfer between the enzyme active site and an electrode mediated with phenothiazine (PTZ). Both electrode reactions were achieved with ChOx attached to the electrode surface by the same immobilisation procedure: enzyme entrapment within the bulk

of a sol-gel membrane deposited from media with high content of organic solvent ${ }^{32,33}$. The combination of both electrochemical reduction and oxidation processes led to a membrane-free, self-powered cholesterol biosensor for whole plasma analysis, which showed enhanced analytical performance compared to the single working electrode counterparts.

\section{EXPERIMENTAL SECTION}

\section{Chemicals}

All inorganic salts, 2-propanol (anhydrous, $99.5 \%$ ), phenothiazine, Triton X-100 and $\gamma$ aminopropyltriethoxysiloxane (APTES) were obtained at the highest purity from Sigma Aldrich (Sweden). Cholesterol oxidase from Streptomyces sp. (lyophilised powder, $\geq 20 \mathrm{U} \mathrm{mg}^{-1}$ protein), cholesterol (powder, BioReagent, suitable for cell culture, $\geq 99.0 \%$ ) were also purchased from Sigma Aldrich (Sweden). Experiments were carried out with Milli-Q water from a Millipore MilliQsystem.

Cholesterol is sparingly soluble in aqueous solutions. There are many different procedures for the preparation of a homogeneous cholesterol solution described in the literature. We used the method described by Vidal et al. ${ }^{34}$ : a stock solution of $15 \mathrm{mM}$ cholesterol was prepared in phosphate buffer (50 mM, pH 6.8) with $0.1 \mathrm{M} \mathrm{KCl}$ as a supporting electrolyte containing $15 \%(\mathrm{w} / \mathrm{w})$ of Triton 
$\mathrm{X}-100$ in a thermostated bath at $65{ }^{\circ} \mathrm{C}$. This solution was stored at $4{ }^{\circ} \mathrm{C}$ in the dark and was stable for at least 10-15 days (when turbidity was observed). More dilute working solutions of cholesterol were prepared by dilution of the stock solution using a $50 \mathrm{mM}$ phosphate buffer solution containing $1 \%(\mathrm{w} / \mathrm{w})$ of Triton $\mathrm{X}-100$.

Blood samples were obtained from healthy donors at the local blood-bank (Blodtappen Linköping, Sweden). The samples, collected in heparin tubes, where used fresh or stored frozen at $-80{ }^{\circ} \mathrm{C}$ until use.

\section{Apparatus}

An Autolab type III potentiostat (Autolab, EcoChemie, Netherlands) and an EmStat USB potentiostat (Palm Instruments, Netherlands) were employed for voltammetric and amperometric measurements. $\mathrm{An} \mathrm{Ag} / \mathrm{AgCl}$ electrode in $3 \mathrm{M} \mathrm{KCl}$ and a platinum wire were used as reference electrode and counter electrode, respectively.

The screen-printed electrode (SPE) system with a graphite working electrode (diameter $1.9 \mathrm{~mm}$ ), a graphite auxiliary electrode, and a $\mathrm{Ag} / \mathrm{AgCl}$ pseudo-reference electrode were purchased from Rusens LTD (Moscow, Russia).

A carbon cloth electrode (CCE, specific surface of ca. $10 \mathrm{~m}^{2} \mathrm{~g}^{-1}$, resistivity of ca. $0.04 \Omega \mathrm{cm}$, the pyrographite overweight was 10\%) ${ }^{35,36}$ from Electrougli NIPT of Carbon Wares (Russia) was used as a working electrode (geometrical surface area of ca. $0.2 \mathrm{~cm}^{2}$ ) in the self-powered biosensor configuration.

A Rotina $380 \mathrm{R}$ (Andreas Hettich $\mathrm{GmbH} \& \mathrm{Co.KG}$ ) centrifuge was used for plasma preparation. Cholesterol measurements in plasma were compared with those obtained using the commercially available BioVision Cholesterol/Cholesteryl Ester Quantitation Kit II, based on a spectroscopic detection of the product of enzymatic oxidation of cholesterol at $450 \mathrm{~nm}$. An ELx800 Absorbance Microplate Reader (Bio-Tek) was used for the spectroscopic detection of cholesterol.

\section{Construction of PB-based modified electrodes}


The SPE and the CCE were modified with PB films by chemical deposition as described previously ${ }^{37}$. A growing solution containing $5 \mathrm{mM} \mathrm{K}_{3}\left[\mathrm{Fe}(\mathrm{CN})_{6}\right]$ and $5 \mathrm{mM} \mathrm{FeCl}_{3}$ in a mixture of $0.1 \mathrm{M} \mathrm{HCl}$ and $0.1 \mathrm{M} \mathrm{KCl}$ was dropped onto the surface of the working electrode. Deposition was initiated adding a reductant (hydrogen peroxide) to the drop on the surface of the working electrode to a final concentration of $100 \mathrm{mM}$. After $45 \mathrm{~min}$ of deposition the treated electrode was washed with water. The PB-modified electrodes were characterised by cyclic voltammetry in $0.1 \mathrm{M} \mathrm{KCl}$, $0.1 \mathrm{M} \mathrm{HCl}$.

\section{Construction of the cathode (ChOx-PB-modified electrodes)}

The ChOx-PB-modified electrodes (Fig. 1A) were fabricated using the same protocol as reported previously ${ }^{32}$. Enzyme immobilisation was carried out from a water-organic mixture with a high content of organic solvent. $15 \mu \mathrm{L}$ of an aqueous solution of the $\mathrm{ChOx}\left(10 \mathrm{mg} \mathrm{mL}^{-1}\right)$ was suspended in $75 \mu \mathrm{L}$ of an isopropanol solution of $0.3 \%$ APTES. The resulting mixture $(2 \mu \mathrm{L})$ was applied with a syringe onto the surface of the PB modified working electrode covering its entire surface and dried in a refrigerator $\left(4^{\circ} \mathrm{C}\right)$ for an hour. The biosensor characterisation was carried out in 50 $\mathrm{mM}$ phosphate buffer saline (PBS) $\mathrm{pH} 6.8$ solutions containing $0.1 \mathrm{M} \mathrm{KCl}$ as a supporting electrolyte and $1 \%(\mathrm{w} / \mathrm{w})$ of Triton X-100.

\section{Construction of the anode (PTZ-ChOx-modified electrodes)}

The PTZ-ChOx-modified SPE and CCE (Fig. 2A) were constructed as described previously ${ }^{38} .15$ $\mu \mathrm{L}$ of an aqueous solution of the ChOx was suspended in $75 \mu \mathrm{L}$ of an isopropanol solution of $1 \%$ APTES containing $5 \mathrm{mM}$ PTZ. The resulting mixture $(2 \mu \mathrm{L})$ was dropped on the surface of the working electrode and dried in a refrigerator $\left(4^{\circ} \mathrm{C}\right)$. The biosensor response was assayed in 50 mM PBS (pH 6.8).

\section{Self-powered detection of cholesterol}


A self-powered cholesterol biosensor was developed by combining the ChOx-PB-modified CCE as cathode with the PTZ-ChOx-modified CCE as anode. Open circuit potentials were obtained in $50 \mathrm{mM}$ PBS (pH 6.8) before and after additions of the cholesterol solution. The polarisation curves were taken from $0 \mathrm{~V}$ to open circuit potential with a scan rate of $1 \mathrm{mV} \mathrm{s}^{-1}$.

\section{Real sample analysis}

For cholesterol measurements platelet poor plasma (PPP) was prepared from human whole blood collected from 5 apparently healthy, consenting blood donors at Linkoping University Hospital. The blood was centrifuged for $20 \mathrm{~min}$ at $480 \mathrm{~g}$. Then the plasma was collected in new tubes. Measurements of free cholesterol were carried out in sheer plasma by the standard addition method, by the ChOx-PB-modified electrode and PTZ-ChOx-modified screen-printed electrodes and by the self-powered biosensor.

\section{RESULTS AND DISCUSSION}

\section{Performance study of the self-powered biosensor counterparts: cathode reaction}

Fig. 1B displays the amperometric response of the ChOx-PB-modified electrode to successive additions of cholesterol solution recorded at $0 \mathrm{~V} v s$ the $\mathrm{Ag} / \mathrm{AgCl}$ internal pseudo-reference electrode. An increase in the reduction current was observed due to the generation of hydrogen peroxide as an enzymatic reaction product being reduced by the electrocatalyst $(\mathrm{PB})$. The current increased in absolute value immediately after the addition of cholesterol and rapidly reached a steady value. The average time required to reach $90 \%$ of the saturation current value was less than 20 s. The concentration of Triton X-100 increased continuously upon successive additions of the cholesterol stock solution; this consequently caused a decrease in the response ${ }^{39}$.

The calibration curve (Fig. 1C) shows the dependence of the response on the cholesterol concentration in the range of $0.05-0.80 \mathrm{mM}(\mathrm{R}=0.9903)$ with a limit of detection of $3.7 \pm 0.2$ $\mu \mathrm{M}$ (calculated as $3 \times \mathrm{SD} /$ sensitivity, where $\mathrm{SD}$ is the standard deviation of the baseline current). The sensitivity assessed from the linear range of the calibration curve was $20.5 \pm 1.5 \mathrm{~mA} \mathrm{M}^{-1} \mathrm{~cm}^{-}$ 
2. The calibration of four different biosensors, produced by simple drop casting of a ChOxcontaining sol membrane onto the working electrode surface, showed a high reproducibility (RSD value of 5.4\%). A comparison of the performance of the cholesterol biosensor developed herein with those of recently reported PB-based cholesterol biosensors is presented in Table 1. Clearly, the developed biosensor possesses improved analytical characteristics, wide dynamic range combined with relatively high sensitivity, in comparison with some available cholesterol biosensors developed on the same transducer.

The calibration curve was plotted in double reciprocal coordinates (Inset to Fig. $1 \mathrm{C}$ ) according to the electrochemical version of the Lineweaver-Burk equation ${ }^{40}$ :

$$
\frac{1}{I_{s s}}=\frac{1}{I_{\max }}+\frac{K_{m}^{a p p}}{I_{\max }}\left(\frac{1}{C}\right)
$$

where $I_{\mathrm{ss}}$ is the steady-state current after the addition of the substrate, $C$ is the substrate bulk concentration and $I_{\max }$ is the maximum current measured under saturated substrate conditions. The apparent Michaelis-Menten constant $\mathrm{K}_{\mathrm{m}}(\mathrm{app})$, an essential parameter to describe the enzymesubstrate kinetics of the biosensor, was calculated from eq. (1). The $\mathrm{K}_{\mathrm{m}}$ (app) value was $0.76 \mathrm{mM}$, which is smaller than the values reported for ChOx immobilised into a sol-gel derived nanostructured cerium oxide matrix $(2.08 \mathrm{mM})^{41}$ and for free ChOx $(3.9 \mathrm{mM}){ }^{6}$; this result illustrates the absence of diffusion limitation for the substrate by the sol-gel matrix. Ideally, for fuel cell operation the substrate should be available at concentrations well above $\mathrm{K}_{\mathrm{m}}(\mathrm{app})^{30}$. Thus, the developed cathode shows a $K_{m}$ (app) value that is compatible with those required for the selfpowered biosensor to operate in biological fluids.

\section{Performance study of the self-powered biosensor counterparts: anode reaction}

Fig. 2B shows the amperometric response of the PTZ-ChOx-modified electrode to successive additions of cholesterol solution. The increase of the anodic current is due to a contribution of the redox-active mediator PTZ in the cholesterol oxidation catalyzed by ChOx. Current responses were observed with cholesterol additions from 0.015 to $0.955 \mathrm{mM}$. The sensitivity of analysis 
assessed from the linear range of the calibration curve was $33.1 \pm 1.3 \mathrm{~mA} \mathrm{M}^{-1} \mathrm{~cm}^{-2}$ with a detection limit of $2.3 \mu \mathrm{M}(3 \times \mathrm{SD} /$ sensitivity). The response time was $10 \mathrm{~s}$. The $\mathrm{RSD}$ value for the reproducibility of the biosensor production procedure $(n=4)$ was $5.0 \%$.

The analytical characteristics of the developed cholesterol biosensor based on oxidation by mediated ChOx were compared with data reported recently (Table 2). The sensitivity observed is among the highest reported values with the linear range consistent with cholesterol concentrations in blood.

The apparent Michaelis-Menten constant $\mathrm{K}_{\mathrm{m}}$ (app) for the cholesterol oxidation (Inset to Fig. 2C) was $0.14 \mathrm{mM}$. It is a lower value than those of previously reported reagentless cholesterol biosensors based on mediated $\mathrm{ChOx}$ 9, 6, 7. The elaborated anode possessed a $\mathrm{K}_{\mathrm{m}}$ (app) value suitable for construction of a self-powered biosensor for blood analysis.

\section{Performance study of the self-powered biosensor counterparts: interferences}

The influences of some possible interfering compounds on the cathodic and anodic current responses to cholesterol were investigated. The amperometric responses to cholesterol $(0.1 \mathrm{mM}$ and $0.25 \mathrm{mM}$ in cathodic and anodic systems respectively) in the presence of $0.5 \mathrm{mM}$ ascorbic acid, $0.5 \mathrm{mM}$ uric acid, $5 \mathrm{mM}$ glucose and $2 \mathrm{mM}$ lactic acid, which are possible interferences in the determination of cholesterol in blood, were measured and compared. (Fig. S1). In spite of the high interferent-to-cholesterol concentration ratios, no significant interference (significance level $5 \%$ ) with either the cathodic or anodic processes was observed.

\section{Self-powered cholesterol biosensor}

The developed cathodic and anodic electrode systems deliver a power output proportional to the cholesterol concentration. Thus, the current passing between a shorted or resistance-circuited cathode and anode is an analytical signal, which could be measured by a simple instrument, such as a multimeter. Combination of the two developed systems allowed us to construct a one- 
compartment single-enzyme based biofuel cell with anode and cathode powered by the same substrate.

The measurements with standard SPEs modified with ChOx in a fuel cell-type configuration did not show current values useful for reliable registration (data not shown). In order to achieve higher signal output, filament CCEs of high surface area were used for the fabrication of both ChOxmodified cathode and anode.

The analytical characteristics of the filament CCE-based enzyme electrodes, as separate counterparts of a self-powered biosensor, towards cholesterol quantification (Fig. S2 and S3) showed sensitivities (estimated from the linear parts of the calibration curves) of $19.4 \pm 0.5 \mathrm{~mA}$ $\mathrm{M}^{-1} \mathrm{~cm}^{-2}$ and $13.8 \pm 0.7 \mathrm{~mA} \mathrm{M}^{-1} \mathrm{~cm}^{-2}$ for the cathode and anode systems, respectively.

Fig. 3A shows the background-subtracted polarisation curves of the ChOx-based filament anode and cathode in a quiescent $0.5 \mathrm{mM}$ cholesterol solution. An anodic current increase due to electrocatalytic oxidation of cholesterol by PTZ-mediated ChOx is observed at $+0.26 \mathrm{~V}$ and reaches a peak current density of $100 \mu \mathrm{A} \mathrm{cm}^{-2}$ at $+0.35 \mathrm{~V}$. A cathodic current increase due to electrocatalytic reduction of hydrogen peroxide, is observed at $+0.37 \mathrm{~V}$ and reaches a steady-state plateau current density of $61.8 \mu \mathrm{A} \mathrm{cm}^{-2}$ at $+0.22 \mathrm{~V}$, which is lower than the electrocatalytic current density obtained at the anode. This indicates that the cathode process is rate-determining and, therefore, it limits the performance of the cholesterol self-powered biosensor.

Fig. 3B displays the power curve of the cell in a quiescent $0.5 \mathrm{mM}$ cholesterol solution. The open circuit potential is estimated to be $109 \mathrm{mV}(\mathrm{RSD}=3.5 \%, \mathrm{n}=3)$. A maximum power density of $11.4 \mu \mathrm{W} \mathrm{cm} \mathrm{cm}^{-2}$ is reached at $53 \mathrm{mV}(\mathrm{RSD}=4.0 \%, \mathrm{n}=3)$. A maximum power density of $11.4 \mu \mathrm{W}$ $\mathrm{cm}^{-2}$ is reached at $53 \mathrm{mV}(\mathrm{RSD}=4.0 \%, \mathrm{n}=3)$. This is comparable to power densities used to supply a PB-based electrochromic display (around $10 \mu \mathrm{W} \mathrm{cm} \mathrm{cm}^{-2}$ ) in the only published, truly selfpowered and integrated analytical device up-to-date ${ }^{28}$. The OCP obtained here is lower than the value used for electrochromic display operation $(0.55 \mathrm{~V})$ and can be increased by changing mediator. 
Both open circuit potential and power density of the cell correlated with cholesterol concentrations (Fig. S4). However, short circuit current measurements, offering a rapid response and easy operation, were used for the studies of the concentration dependence (Fig. 4A). The addition of cholesterol into the cell led to an increase of the current due to electrode reactions of the mediator or hydrogen peroxide. Knowing the rise of the current density upon cholesterol concentration increase and assuming a linear time dependence, one can estimate the quantity of electricity transferred during the elapsed time. The number of the converted molecules was calculated from Faraday's law. The rate of the Faradaic process, calculated as the number of molecules converted per unit of time, was $7.5 \times 10^{12}$ molecules $\mathrm{s}^{-1}$ for self-powered configuration, which is three times higher than for cathodic and anodic systems alone $\left(2.7 \times 10^{12}\right.$ molecules $\mathrm{s}^{-1}$ and $2.0 \times 10^{12}$ molecules $\mathrm{s}^{-1}$ respectively). The higher reaction rate for the self-powered device compared to the sum of the rates for cathode and anode, probably indicates the involvement of hydrogen peroxide formed as a parasitic side product of the anodic reaction resulting in reduction at the cathode, which is located only a short distance away (ca. $1 \mathrm{~mm}$ ). The possible generation of the hydrogen peroxide by the anode-mediated enzyme reduces the anode efficiency. However, as the cathode gives almost two times smaller current density than anode and is located in close vicinity to the anode, allowing the involvement of the anode-leaked peroxide into the electrode reaction, decrease of the anode efficiency will probably not influence the performance significantly.

In contrast to the instability of the self-charging biosupercapacitor reported recently by Shleev et al. ${ }^{29}$ operating in galvanostatic charge-discharge mode, only a minor steady-state current instability was observed for the cholesterol self-powered biosensor, which probably illustrates the favorable measurement mode for this type of analytical devices based on enzyme-modified filament electrodes.

The calibration plot of the short circuit amperometric responses (Fig. 4B) shows a sensitivity of cholesterol detection, assessed from the linear range of the calibration curve, of $26.0 \pm 0.5 \mathrm{~mA} \mathrm{M}^{-}$ ${ }^{1} \mathrm{~cm}^{-2}$ and a detection limit of $1.4 \mu \mathrm{M}(3 \times \mathrm{SD} /$ sensitivity). The dynamic range for cholesterol 
detection is from $0.15 \mathrm{mM}$ to $4.1 \mathrm{mM}(\mathrm{R}=0.994)$. A comparison of all analytical characteristics of cholesterol quantification (Table 3) shows higher sensitivity values obtained for the selfpowered configuration in comparison with the characteristics measured separately for the corresponding cathodic and anodic counterparts. Thus, a gain in biosensor analytical performance can be obtained by a combination of both electrodes powered by the same substrate. A particularly interesting phenomenon is the larger sensitivity of the self-powered configuration in comparison with the characteristics of the cathode process, which limits the performance of a fuel cell assembled with the isolated counterparts. This illustrates a valuable contribution of the membranefree configuration: an efficiency increase due to the reduction on the cathode of hydrogen peroxide formed as a side product of the anodic reaction. The biocatalyst-based substrate selectivity of both counterparts allows cell operation in a membrane-free configuration, which maximises the power output as an analytical signal available for simple instrument measurements. The current densities obtained are high enough to power electrochromic display ${ }^{28}$. Thus, the developed approach could be used in further development of fully integrated analytical devices for personal remote monitoring.

\section{Real sample analysis}

Due to the background response instability during long-term amperometry in plasma, the current transients recorded on both SPE and filament CCE after $30 \mathrm{~s}$, which corresponds to almost steadystate values, were used as analytical response (for model solutions, see Fig. S5). The sensitivities obtained in model solution with SPE-based cathode and anode were $8.8 \pm 0.6 \mathrm{~mA} \mathrm{M}^{-1} \mathrm{~cm}^{-2}$ and $12.2 \pm 0.8 \mathrm{~mA} \mathrm{M}^{-1} \mathrm{~cm}^{-2}$, respectively, which is lower than obtained for the amperometry measurements, probably due to higher contribution from non-Faradic processes at shorter times. Utilising this measurement mode, the upper level of the dynamic range for cholesterol determination was increased allowing measurements in undiluted human plasma.

The cholesterol concentrations in plasma were measured by the standard addition method (Fig. S6) on both SPE-based cathodic and anodic systems, RSD values $(\mathrm{n}=5)$ were $7.5 \%$ and $5.8 \%$, 
respectively. The obtained data showed a good correlation with the results of the standard kit for free cholesterol evaluation in plasma based on spectroscopy (Fig. 5). Due to the wider dynamic range, the anode system based on mediated ChOx showed a high correlation with the standard method for all available plasma samples.

The cholesterol concentrations measured with the filament CCE-based self-powered biosensor showed a linear correlation with the values obtained by the standard kit (Fig. 5). However, the analyte content values assessed with the self-powered biosensor were 27-32\% lower than the values obtained by the standard kit, probably due to adsorption of blood components onto the filament structure of the CCEs during the measurement time. This effect was confirmed by a significant decrease in electrode surface area during the course of the experiment (20 min) as indicated by impedance spectroscopy (Fig. S7 and Supporting Note 1).

The results obtained shows the feasibility of cholesterol measurements with a self-powered biosensor in plasma and could be used for further development of analytical devices for distributed diagnosticsimplantable devices.

\section{CONCLUSIONS}

Novel reagentless electrochemical cholesterol biosensors were developed utilising the electrocatalytic reduction of hydrogen peroxide as a product of enzymatic cholesterol conversion and bioelectrocatalytic cholesterol oxidation by mediated cholesterol oxidase. The enzyme entrapment into a sol-gel membrane was used as a highly effective immobilisation strategy for both cathode and anode fabrication. The sensitivities, linear ranges, limits of detection and interference effects assessed for both electrode systems separately showed very good system performance.

The combination of the cathodic and the anodic systems allowed the development of a novel single enzyme, membrane-free, self-powered cholesterol biosensor with a short circuit current output as an analytical signal indicative of the cholesterol concentration. This novel strategy resulted in a 
sensitivity increase (up to $26.0 \mathrm{~mA} \mathrm{M} \mathrm{M}^{-1} \mathrm{~cm}^{-2}$ with a dynamic range up to $4.1 \mathrm{mM}$ ) in comparison with the separate counterparts.

The high specificity of detection due to the biocatalyst involvement at both electrocatalytic electrodes and to optimised operational conditions allowed reagenteless electrochemical measurements of free cholesterol in plasma, which correlated well with the standard method.

The electrical simplicity (minimal signal processing) of this approach could be extremely useful in a fully-integrated analytical device for personal cholesterol monitoring exploiting silicon-free printed electronics ${ }^{20}$.

\section{ACKNOWLEDGMENTS}

The authors would like to thank The Swedish research council Formas and the research centre Security Link for financial support. A.N.S thanks the Swedish Institute for the award of the Scholarship within the Visby Program.

\section{ASSOCIATED CONTENT}

Additional information including results of the interference study, figures and the data of the biofoling investigation on the CCE is available free of charge via Internet at http://pubs.acs.org/. 


\section{REFERENCES}

(1) Semenkovich, C. F. Cecil Medicine 2007, 217.

(2) Shen, J.; Liu, C. C. Sens. Actuator B-Chem. 2007, 120, 417-425.

(3) MacLachlan, J.; Wotherspoon, A. T. L.; Ansell, R. O.; Brooks, C. J. W. J. Steroid Biochem. Mol. Biol. 2000, 72, 169-195.

(4) Arya, S. K.; Datta, M.; Malhotra, B. D. Biosens. Bioelectron. 2008, 23, 1083-1100.

(5) Kumar, A.; Rajesh; Chaubey, A.; Grover, S. K.; Malhotra, B. D. J. Appl. Polym. Sci. 2001, 82, 3486-3491.

(6) Ozer, B. C.; Ozyoruk, H.; Celebi, S. S.; Yildiz, A. Enzyme Microb. Technol. 2007, 40, 262265.

(7) Huang, Q.; An, Y.; Tang, L.; Jiang, X.; Chen, H.; Bi, W.; Wang, Z.; Zhang, W. Anal. Chim. Acta 2011, 707, 135-141.

(8) Fang, C.; He, J.; Chen, Z. Sens. Actuator B-Chem. 2011, 155, 545-550.

(9) Vidal, J. C.; Garcia, E.; Castillo, J. R. Anal. Sci. 2002, 18, 537-542.

(10) Ding, S.-N.; Shan, D.; Zhang, T.; Dou, Y.-Z. J. Electroanal. Chem. 2011, 659, 1-5.

(11) Manesh, K. M.; Santhosh, P.; Gopalan, A. I.; Lee, K. P. Electroanalysis 2010, 22, 2467-2474.

(12) Vidal, J. C.; Espuelas, J.; Garcia-Ruiz, E.; Castillo, J. R. Talanta 2004, 64, 655-664.

(13) Karimi, S.; Ghourchian, H.; Rahimi, P.; Rafiee-Pour, H. A. Anal. Methods 2012, 4, 32253231.

(14) Manjunatha, R.; Shivappa Suresh, G.; Savio Melo, J.; D'Souza, S. F.; Venkatarangaiah Venkatesha, T. Talanta 2012, 99, 302-309.

(15) Salimi, A.; Hallaj, R.; Soltanian, S. Electroanalysis 2009, 21, 2693-2700.

(16) Umar, A.; Rahman, M. M.; Vaseem, M.; Hahn, Y.-B. Electrochem. Commun. 2009, 11, 118121.

(17) Brahim, S.; Narinesingh, D.; Guiseppi-Elie, A. Anal. Chim. Acta 2001, 448, 27-36.

(18) Kumar, S.; Singh, J.; Agrawal, V. V.; Ahamad, M.; Malhotra, B. D. Anal. Methods 2011, 3, 2237-2245.

(19) Zhu, L.; Xu, L. L.; Tan, L.; Tan, H.; Yang, S. F.; Yao, S. Z. Talanta 2013, 106, 192-199.

(20) Turner, A. P. F. Chem. Soc. Rev. 2013, 42, 3184-3196.

(21) Wingard, L. B. Diabetes Care 1982, 5, 222-223. 
(22) Davis, G.; Hill, H. A. O.; Aston, W. J.; Higgins, I. J.; Turner, A. P. F. Enzyme Microb. Technol. 1983, 5, 383-388.

(23) Newman, J. D.; Turner, A. P. F. Biosens. Bioelectron. 2005, 20, 2435-2453.

(24) Katz, E.; Buckmann, A. F.; Willner, I. J. Am.Chem.Soc. 2001, 123, 10752-10753.

(25) Kakehi, N.; Yamazaki, T.; Tsugawa, W.; Sode, K. Biosens. Bioelectron. 2007, 22, 2250-2255.

(26) Deng, L.; Chen, C. G.; Zhou, M.; Guo, S. J.; Wang, E. K.; Dong, S. J. Anal.Chem. 2010, 82, 4283-4287.

(27) Wen, D.; Deng, L.; Guo, S. J.; Dong, S. J. Anal.Chem. 2011, 83, 3968-3972.

(28) Zloczewska, A.; Celebanska, A.; Szot, K.; Tomaszewska, D.; Opallo, M.; JönssonNiedziolka, M. Biosens. Bioelectron. 2014, 54, 455-461.

(29) Pankratov, D.; Blum, Z.; Suyatin, D. B.; Popov, V. O.; Shleev, S. ChemElectroChem 2014, $1,343-346$.

(30) Cracknell, J. A.; Vincent, K. A.; Armstrong, F. A. Chem. Rev. 2008, 108, 2439-2461.

(31) Krikstolaityte, V.; Oztekin, Y.; Kuliesius, J.; Ramanaviciene, A.; Yazicigil, Z.; Ersoz, M.; Okumus, A.; Kausaite-Minkstimiene, A.; Kilic, Z.; Solak, A. O.; Makaraviciute, A.; Ramanavicius, A. Electroanalysis 2013, 25, 2677-2683.

(32) Yashina, E. I.; Borisova, A. V.; Karyakina, E. E.; Shchegolikhina, O. I.; Vagin, M. Y.; Sakharov, D. A.; Tonevitsky, A. G.; Karyakin, A. A. Anal.Chem. 2010, 82, 1601-1604.

(33) Sekretaryova, A. N.; Vokhmyanina, D. V.; Chulanova, T. O.; Karyakina, E. E.; Karyakin, A. A. Anal.Chem. 2012, 84, 1220-1223.

(34) Vidal, J.-C.; Espuelas, J.; Garcia-Ruiz, E.; Castillo, J.-R. Talanta 2004, 64, 655-664.

(35) Baver, A. I.; Kovaleva, N. V.; Mishina, G. A.; Semenova, L. P. Fibre Chem. 1977, 9, 76-79.

(36) Karyakin, A. A.; Vagin, M. Y.; Ozkan, S. Z.; Karpachova, G. P. J. Phys. Chem. B 2004, 108, 11591-11595.

(37) Sitnikova, N. A.; Borisova, A. V.; Komkova, M. A.; Karyakin, A. A. Anal.Chem. 2011, 83, 2359-2363.

(38) Sekretaryova, A. N.; Vagin, M. Y.; Beni, V.; Turner, A. P. F.; Karyakin, A. A. Biosens. Bioelectron. 2014, 53, 275-282.

(39) Gopalan, A. I.; Lee, K.-P.; Ragupathy, D. Biosens. Bioelectron. 2009, 24, 2211-2217.

(40) Kamin, R. A.; Wilson, G. S. Anal.Chem. 1980, 52, 1198-1205.

(41) Ansari, A. A.; Kaushik, A.; Solanki, P. R.; Malhotra, B. D. Electrochem. Commun. 2008, 10, 1246-1249. 
(42) Li, J. P.; Peng, T. Z.; Peng, Y. Q. Electroanalysis 2003, 15, 1031-1037.

(43) Tan, X. C.; Ll, M. J.; Cai, P. X.; Luo, L. J.; Zou, X. Y. Anal. Biochem. 2005, 337, 111-120.

(44) Li, J. P.; Gu, H. N. J. Chin. Chem. Soc. 2006, 53, 575-582.

(45) Ohnuki, H.; Honjo, R.; Endo, H.; Imakubo, T.; Izumi, M. Thin Solid Films 2009, 518, 596599.

(46) Hernandez-Cruz, M.; Galan-Vidal, C. A.; Alvarez-Romero, G. A.; Ramirez-Silva, M. T.; Paez-Hernandez, M. E.; Gonzalez-Vidal, J. L. J. Mex. Chem. Soc. 2013, 57, 47-72.

(47) Liu, X.; Nan, Z.; Qiu, Y.; Zheng, L.; Lu, X. Electrochim. Acta 2013, 90, 203-209.

(48) Torres, A. C.; Ghica, M. E.; Brett, C. M. A. Electroanalysis 2012, 24, 1547-1553.

(49) Kakhki, S.; Barsan, M. M.; Shams, E.; Brett, C. M. A. Anal. Methods 2013, 5, 1199-1204. 


\section{FIGURE LEGENDS}

Figure 1. The response of the cathode system to cholesterol. A: Scheme of the cathode system. B: An example of amperometric response of the ChOx-PB-modified SPE to successive additions of cholesterol solution (the total concentrations are given in the calibration curve) at $0 \mathrm{~V}$ potential (50 mM PBS (pH 6.8), 1\% Triton X-100); C: Calibration curve for the ChOx-PB-modified SPE. Inset: Double reciprocal plot of the calibration curve.

Figure 2. The response of the anode system to cholesterol. A: Scheme of the anode system. B: An example of amperometric response of the PTZ-ChOx-modified SPE to successive additions of cholesterol solution (the total concentrations are given by the first 8 points of the calibration curve) at 0.3 V potential (50 mM PBS (pH 6.8), 1\% Triton X-100); C: Calibration curve for PTZ-ChOxmodified SPE. Inset: Double reciprocal plot of the calibration curve.

Figure 3. Energetics of the self-powered cholesterol biosensor. A: Scheme of the single enzyme based self-powered membrane-free cholesterol biosensor; B: Background-subtracted polarization curves of the PTZ-ChOx-modified CCE (black curve) and of the ChOx-PB-modified CCE (red curve); C: Dependence of the power density on the cell voltage. Quiescent, air-saturated $0.5 \mathrm{mM}$ cholesterol solution in $50 \mathrm{mM}$ PBS (pH 6.8), $1 \%(\mathrm{~m} / \mathrm{v})$ Triton X-100.

Figure 4. Analytical performance of the self-powered cholesterol biosensor. A: An example of current response to the additions of standard cholesterol solutions, no applied voltage; B: Calibration curve for cholesterol obtained at the self-powered biosensor. Inset: Double reciprocal plot of the calibration curve. Quiescent, air-saturated $50 \mathrm{mM}$ PBS (pH 6.8), 1\% (m/v) Triton X100.

Figure 5. Comparative free cholesterol quantification in plasma. $\bigcirc$ - cathodic system on SPE; anodic system on SPE; - self-powered biosensor on CCEs. 

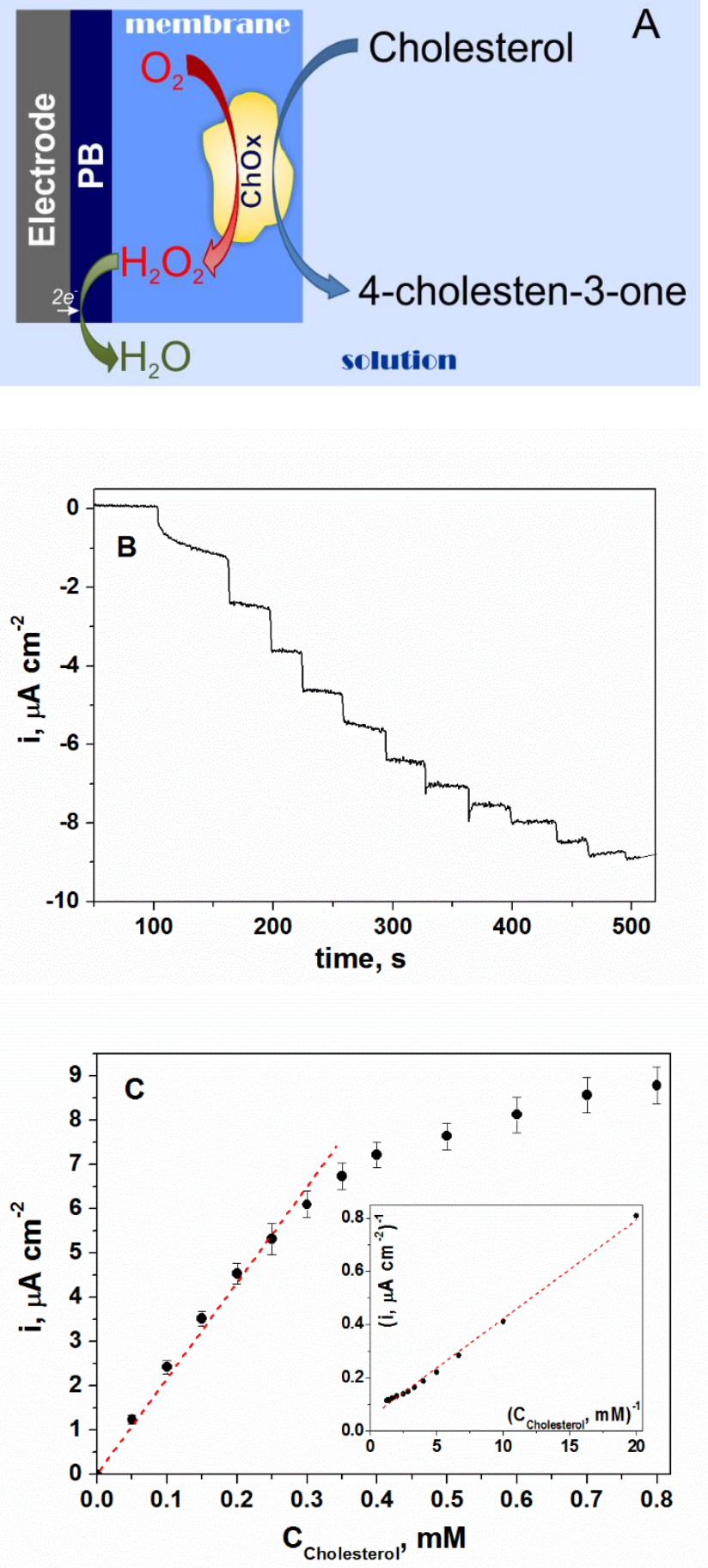

Figure 1. 

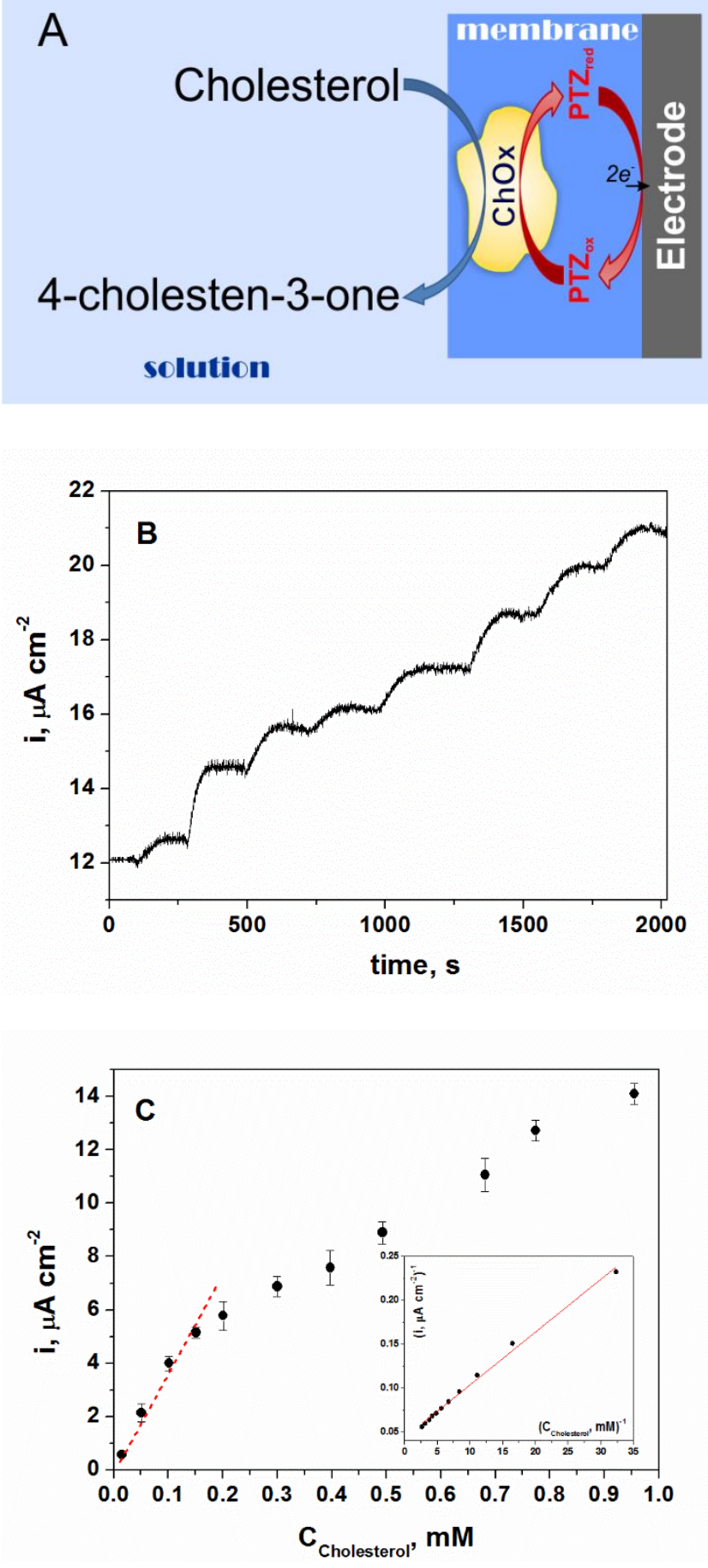

Figure 2. 

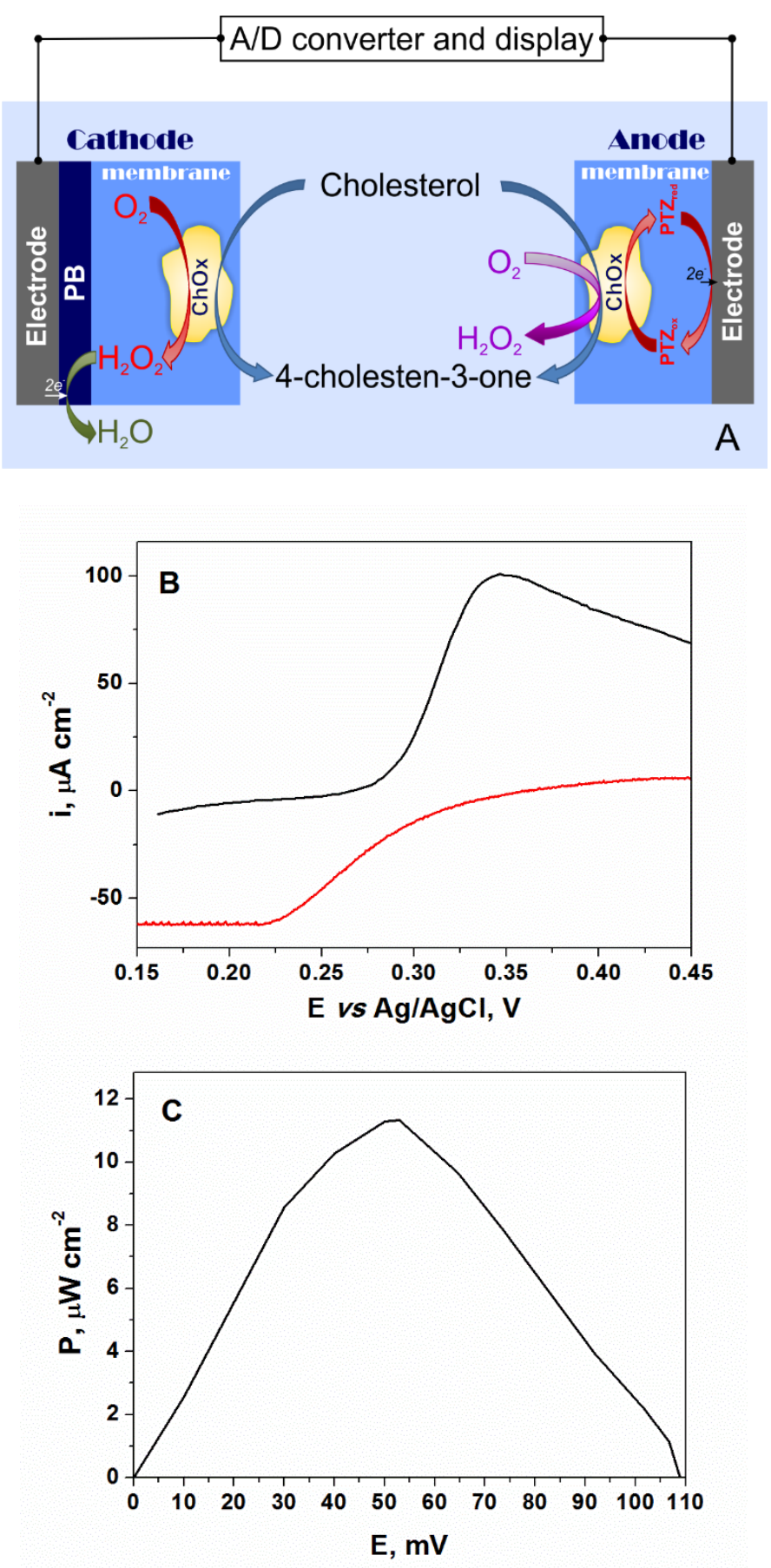

Figure 3. 

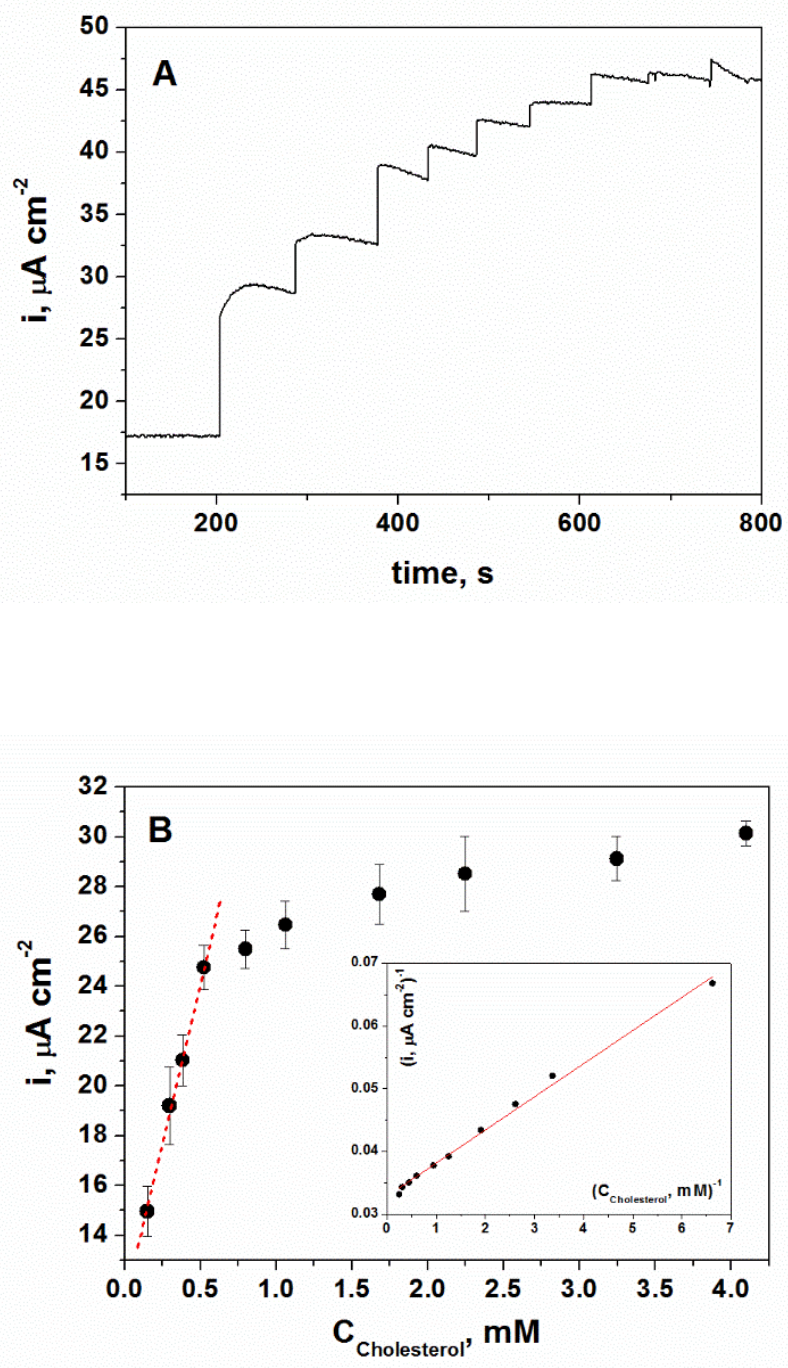

Figure 4. 


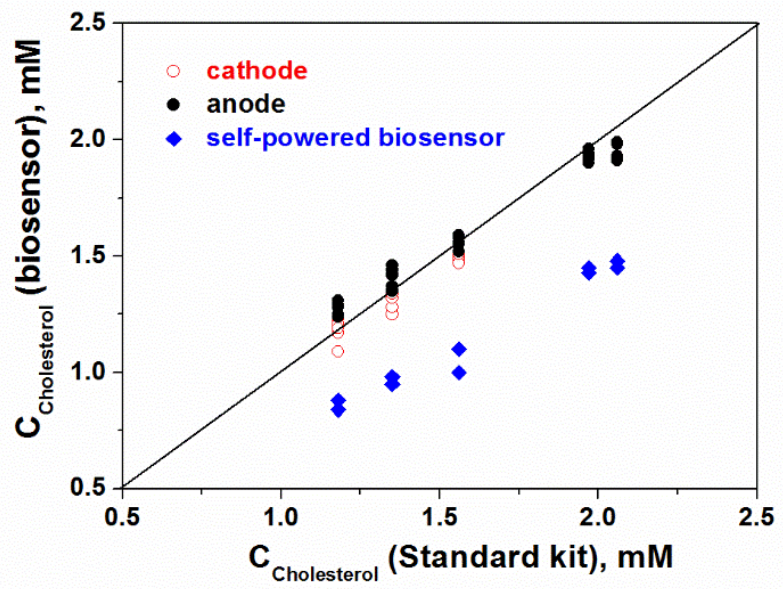

Figure 5. 
Table 1. Analytical characteristics of Prussian blue-based cholesterol biosensors.

\begin{tabular}{|c|c|c|c|c|}
\hline Biosensor configuration & $\begin{array}{l}\text { Linear range, } \\
\mathrm{mM}\end{array}$ & $\begin{array}{l}\text { Detection limit, } \\
\mu \mathrm{M}\end{array}$ & $\begin{array}{l}\text { Sensitivity, } \\
\mathrm{mA} \mathrm{M}^{-1} \mathrm{~cm}^{-2}\end{array}$ & Ref. \\
\hline ChOx/sol-gel/PB/GCE & $0.001-0.08$ & 0.12 & $2.6 \times 10^{-3}$ & 42 \\
\hline Nafion/ChOx-Ppy/PB/SAM/Pt & $0.05-0.3$ & 12 & $8.572 \times 10^{-3}$ & 12 \\
\hline MWCNTs-ChOx-SiO2-chitosan/PB/GCE & $0.004-0.7$ & 1 & $1.55 \mathrm{~mA} \mathrm{M}^{-1}$ & 43 \\
\hline $\mathrm{ChOx} / \mathrm{Ppy} / \mathrm{PB} / \mathrm{GCE}$ & $0.02-0.1$ & 0.6 & 0.55 & 44 \\
\hline ODTA*/PB/ChOx Langmuir-Blodgett film & $0.2-1.2$ & - & 1.6 & 45 \\
\hline ChOx/SPE with PB & $2-16$ & 1290 & 4.1 & 46 \\
\hline Ionic liquid-ChOx/PB/GCE & $0.01-0.4$ & 4.4 & $400 \mathrm{~mA} \mathrm{M}^{-1}$ & 47 \\
\hline ChOx-PB-modified SPE & $0.05-0.30$ & 3.7 & 20.5 & This work \\
\hline
\end{tabular}

*ODTA -octadecyltrimethylammonium bromide 
Table 2. Analytical characteristics of reagentless cholesterol electrochemical biosensors based on mediated ChOx.

\begin{tabular}{|c|c|c|c|c|}
\hline Biosensor configuration & $\begin{array}{l}\text { Linear range, } \\
\mathrm{mM}\end{array}$ & $\begin{array}{l}\text { Detection limit, } \\
\mu \mathrm{M}\end{array}$ & $\begin{array}{l}\text { Sensitivity } \\
\mathrm{mA} \mathrm{M}^{-1} \mathrm{~cm}^{-2}\end{array}$ & Ref. \\
\hline ChOx/Dodecylbenzene sulfonate/Ppy/ITO & $2-8$ & - & - & 5 \\
\hline ChOx/ferrocene monocarboxylic acid/PPy/ Pt/Pt & Up to 0.3 & 12.4 & 1.25 & 9 \\
\hline $\mathrm{ChOx} / \mathrm{Poly}$ (vinylferrocenium)perchlorate/Pt & $0.1-0.5$ & - & 0.14 & 6 \\
\hline ChOx/AuNPs/polythionine/GCE & $0.002-1$ & 0.6 & 2.8 & 7 \\
\hline $\mathrm{ChOx} / 1,10$-phenanthroline-5,6-dione in ink of SPE & $1-10$ & 1000 & 8 & 8 \\
\hline ChOx/poly(neutral red)/carbon film electrode & Up to 0.22 & 1.9 & 0.018 & 48 \\
\hline ChOx/PEDOT*/poly(methylene blue)/GCE & $0.01-0.22$ & 1.6 & 79 & 49 \\
\hline PTZ-ChOx-modified SPE & $0.015-0.15$ & 2.3 & 33.1 & This work \\
\hline
\end{tabular}

*PEDOT - poly(3,4-ethylenedioxythiophene) 
Table 3. Analytical characteristics of cholesterol quantification in model solutions.

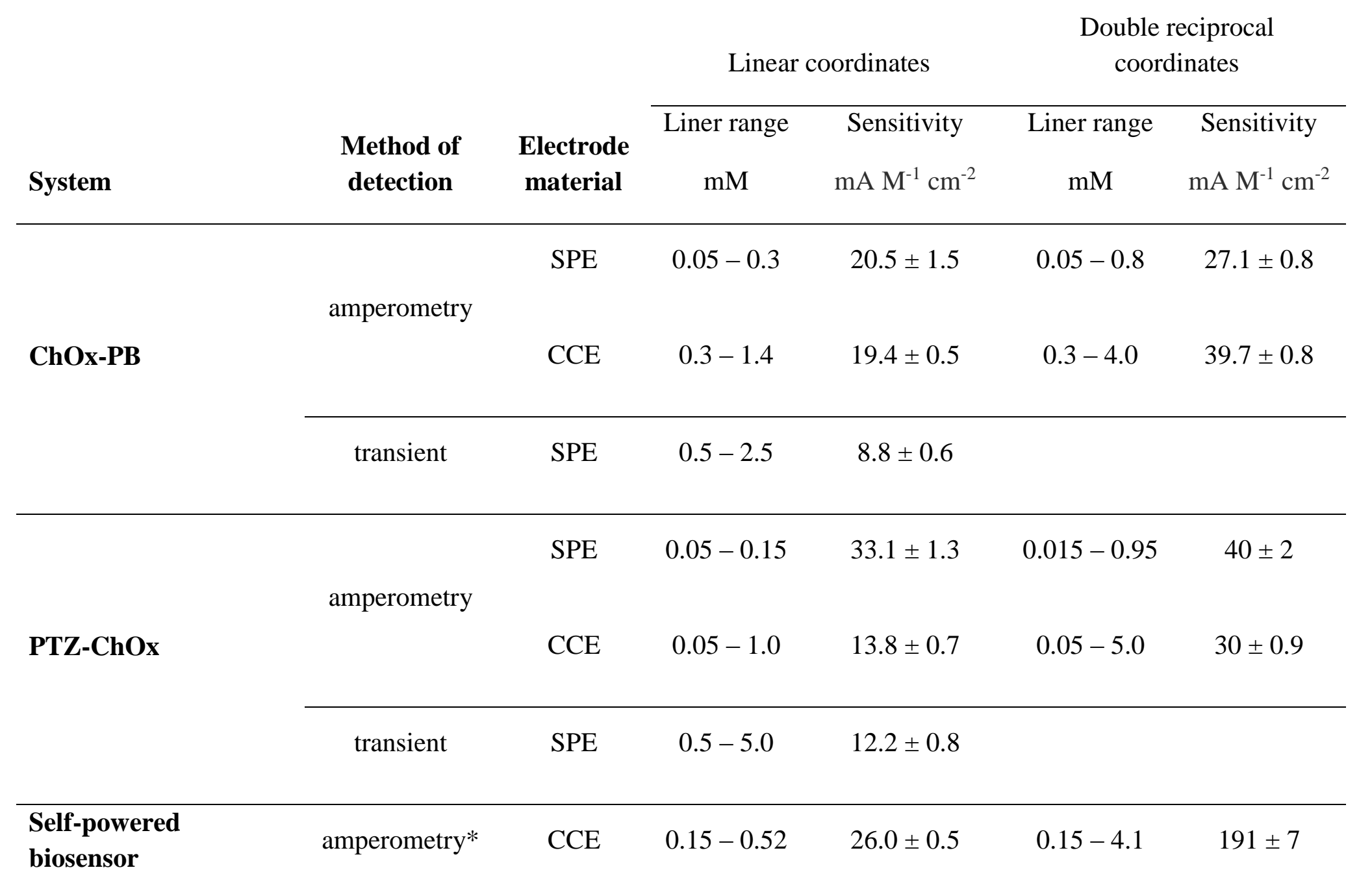

*Short-circuit current 